\title{
Serra Pelada: the first Amazonian Meteorite fall is a Eucrite (basalt) from Asteroid 4-Vesta
}

\author{
MARIA ELIZABETH ZUCOLOTTO ${ }^{1}$, AMANDA A. TOSI ${ }^{2}$, CAIO V.N. VILLAÇA ${ }^{2}$, \\ ANDRÉ L.R. MOUTINHO ${ }^{3}$, DIANA P.P. ANDRADE ${ }^{4}$, FABIANO FAULSTICH ${ }^{1}$, \\ ANGELO M.S. GOMES ${ }^{5}$, DEBORA C. RIOS ${ }^{6}$ and MARCILIO C. ROCHA
}

\author{
${ }^{1}$ LABET/MN/UFRJ, Laboratório Extraterrestre, Departamento de Geologia e Paleontologia, Museu Nacional, \\ Universidade Federal do Rio de Janeiro, Quinta da Boa Vista, São Cristóvão, 20940-040 Rio de Janeiro, RJ, Brazil \\ ${ }^{2}$ LABSONDA/IGEO/UFRJ, Instituto de Geociências, Universidade Federal do Rio de Janeiro, Av. \\ Athos da Silveira Ramos, 274, Cidade Universitária, 21941-972 Rio de Janeiro, RJ, Brazil \\ ${ }^{3}$ Colecionador da International Meteorite Colector Association (IMCA \#2731), \\ R. Roberto dos Santos, 163, 12300-000 Jacareí, SP, Brazil \\ ${ }^{4}$ OV/UFRJ, Observatório do Valongo, Universidade Federal do Rio de Janeiro, Ladeira \\ Pedro Antônio, 43, Saúde, 20080-090 Rio de Janeiro, RJ, Brazil \\ ${ }^{5}$ IF/UFRJ, Instituto de Física, Universidade Federal do Rio de Janeiro, Av. Athos da Silveira \\ Ramos,149, CT, Bloco A, Cidade Universitária, 21941-972 Rio de Janeiro, RJ, Brazil \\ ${ }^{6} \mathrm{GPA}$, Universidade Federal da Bahia/UFBA, Instituto de Geociências, R. Barão \\ de Geremoabo, s/n, Ondina, 40170-290 Salvador, BA, Brazil \\ ${ }^{7}$ Universidade Federal do Pará/UFPA, Departamento de Geociências e Engenharias, Rua Augusto \\ Correa, $n^{\circ}$ 01, Campus Universitário do Guamá, 66075-110 Belém, PA, Brazil
}

Manuscript received on October 24, 2017; accepted for publication on December 11, 2017

\begin{abstract}
Serra Pelada is the newest Brazilian eucrite and the first recovered fall from Amazonia (State of Pará, Brazil, June $29^{\text {th }} 2017$ ). In this paper, we report on its petrography, chemistry, mineralogy and its magnetic properties. Study of four thin sections reveals that the meteorite is brecciated, containing basaltic and gabbroic clasts, as well of recrystallized impact melt, embedded into a fine-medium grained matrix. Chemical analyses suggest that Serra Pelada is a monomict basaltic eucritic breccia, and that the meteorite is a normal member of the HED suite. Our results provide additional geological and compositional information on the lithological diversity of its parent body. The mineralogy of Serra Pelada consists basically of low-Ca pyroxene and high-Ca plagioclase with accessory minerals such as quartz, sulphide (troilite), chromite - ulvöspinel and ilmenite. These data are consistent with the meteorite being an eucrite, a basaltic achondrite and a member of the howardite-eucrite-diogenite (HED) clan of meteorites which most likely are from the crust asteroid 4 Vesta.
\end{abstract}

Key words: Serra Pelada, meteorite, eucrite, Vesta, Brazilian Meteorite.

Correspondence to: Maria Elizabeth Zucolotto

E-mail: meteoritos@mn.ufrj.br 


\section{INTRODUCTION}

Observed meteorite falls are very important for scientific studies, because the recovered material was not yet subjected to terrestrial weathering.

It is believed that the majority of meteorites are originated on parent bodies in the asteroid belts. Although few specific asteroids have been identified as meteorite sources, there is an association between Vesta (and other asteroids in the Vestoid Family) and the Howardite, Eucrite, Diogenite (HEDs) clan of achondrites (Binzel and $\mathrm{Xu}$ 1993). The achondrites are differentiated rocks and were derived from planetary bodies that partially or totally melted. In case of asteroid 4 Vesta, the most likely parent asteroid of the HEDs, this process formed a metallic core, a mafic mantle, and a basaltic crust. This differentiation took place in the very early history of the solar system, and the heat source was short lived ${ }^{26} \mathrm{Al}$ (e.g., Srinivasan et al. 1998, Mittlefehldt et al. 1998, Keil 2002, Mittlefehldt 2005, 2014, 2015).

The eucrites represent volcanic rocks and are subdivided into cumulate and basaltic, based on their pyroxene and plagioclase major-element compositions (McSween et al. 2011). Cumulate eucrites are plutonic rocks (coarse grained equigranular) and primarily composed of anorthite plagioclase $\left(\mathrm{An}_{90-96}\right)$ and $\mathrm{MgO}$-rich pyroxene $\left(\mathrm{En}_{46-}\right.$ ${ }_{65}$ ). Basaltic eucrites are defined by extrusive, i.e., fine- to very fine-grained textures. It is believed that they formed at or near Vesta's surface quickly cooled. They contain pyroxene, FeO-rich $\left(\mathrm{En}_{<46}\right)$, and more sodic plagioclase $\left(\mathrm{An}_{<90}\right)$ than the cumulate (McSween et al. 2011).

Aiming to improve understanding of Vesta magmatic processes, this paper investigates this fresh eucrite fall and describes different textures in the meteorite, as well as the chemical analysis of its minerals.

\section{HISTORY}

The Serra Pelada meteorite fell on June 29, 2017 (10:35 local time - UTC-3) at Serra Pelada Village (a famous gold mining location) $\left(5^{\circ} 57.135^{\prime} \mathrm{S}, 49^{\circ}\right.$ $\left.39.238^{\prime} \mathrm{W}\right)$, located in the State of Pará, northern Brazil. People reported seeing a fireball in the southeast sky of the state, apparently traveling from NE to SW. A large explosion followed by a series of minors ones was heard in nearby towns such as Marabá, Eldorado dos Carajás and Paraopebas. The inhabitants of these localities thought an airplane had fallen. Using helicopters, the Fire and Police departments searched in vain for the accident.

The students and staff of the Rita Lima Sousa Municipal School who were in the playground witnessed the fall of the rock on the sidewalk, after a sequence of four to six explosions. Also observed were a trail of smoke and a little dust caused by the impact. People went to the impact site and collected fragments of the broken stone leaving only a small impact pit.

A second mass of $5.4 \mathrm{~kg}$ was observed to fall and was recovered by an electrician while working at Serra Leste, a Vale do Rio Doce enterprise. This piece was sold to an anonymous buyer. The residents did not realize the importance of the event. They exchanged the fragments among themselves and shared them with local people.

The geologist Marcilio Cardoso Rocha, born at Serra Pelada, was contacted and, suspecting that it was a meteorite, he contacted Dra. Maria Elizabeth Zucolotto (MEZ), the senior author of this paper, who advised him to do some preliminary analyses. Even before Marcílio sent a sample to the Museu Nacional, information about the fall of the meteorite leaked into social medias and shortly dealers went to the place and got many pieces. This event happened while some authors were in the field trying to stablish the strewnfield of Três Irmãos meteorite, which fell in the State of Bahia a month before, which is an unusual fact. 
Some of us went to Serra Pelada in order to determine the strewnfield and possibly retrieve other pieces. The task was complicated due to intrinsic difficulties associated with the region, such as the hot weather, a large area covered by forest or high grass and dangerous conditions, such as: find a clandestine gold prospecting, the need to make large amount of withdrawals, and be stopped at a road closed by the Movement of Landless Workers (MST, Movimento dos Trabalhadores Rurais Sem Terra, in Portuguese). The best place for searching was in the Serra Leste enterprise area, but we have not given permission to explore.

The meteorite classification and the name "Serra Pelada" were approved by the Meteorite Nomenclature Committee of the Meteoritical Society $\mathrm{N}^{\circ} 106$ as a brecciated eucrite.

\section{MATERIALS AND METHODS}

Many slices, such as in figure 1, were examined using a stereomicroscope Zeiss Discovery V8. Three polished thin sections were examined microscopically in transmitted and reflected light using a petrographic microscope (Zeiss Axioplan) and minerals in two polished thin sections were analyzed using a JEOL EPMA JXA-8230 Superprobe at LABSONDA/IGEO/UFRJ.

Quantitative analyses of constituent phases we carried out using Wavelength Dispersive Spectrometry (WDS). Beam conditions included an accelerating voltage of $15 \mathrm{KeV}$, beam current of 20 $\mathrm{nA}$ and a spot size of $1 \mu \mathrm{m}$ for silicates and $20 \mathrm{KeV}$, for opaque minerals. Well-characterized natural and synthetic phases were used as standards, and corrections for differential matrix effects were made with a ZAF factory supplied procedure. During the study, Energy Dispersive Spectrometer (EDS), backscattered electrons (BSE) imaging and composition mapping image by WDS were also performed.

Micro-Raman spectroscopy was conducted with a Horiba Jobin Yvon LabRam HR at CETEM

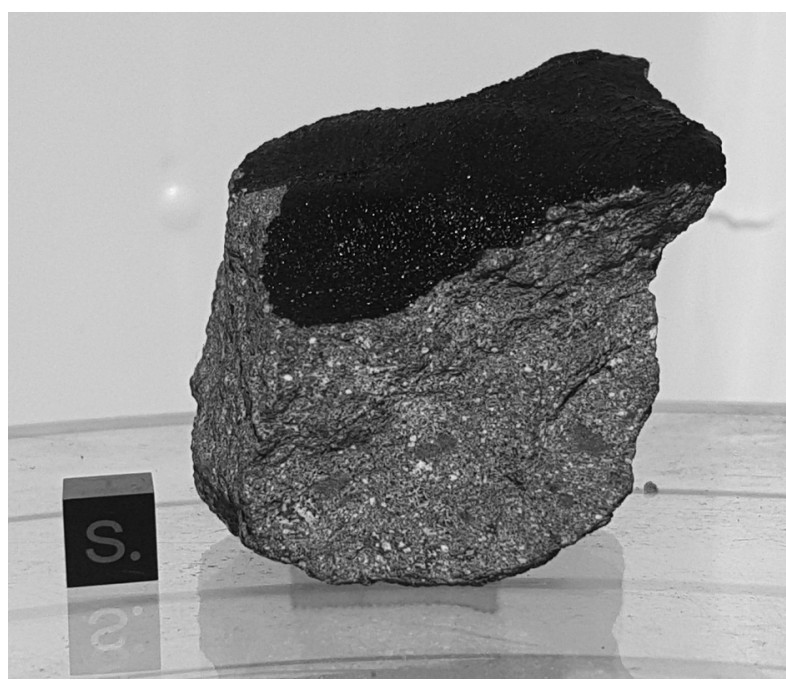

Figure 1 - A cut section of Serra Pelada meteorite. It shows a typical eucrite with a partial, shiny, black fusion crust and a light colored interior with a brecciated texture. Also visible are some cracks and melt veins. Some clasts show clumps of white blades of plagioclase (size of cube $1 \mathrm{~cm}$ ).

(Centro de Tecnologia Mineral). A $632.8 \mathrm{~nm}$ laser standardized with a Si chip and a confocal hole of 300 . The analyses were performed using a 100 $\mathrm{X}$ objective lens on the Raman microscope. The recorded spectra were compared with the RRUFF database for phase identification.

The magnetic data were obtained in a Physical Properties Measurement System, from Quantum Design Inc with Option P500, which uses an extraction technique where the magnetized sample is moved through detection coils. All measurements were performed at room temperature, $\mathrm{T}=300 \mathrm{~K}$, and ramping the magnetic field up to $10 \mathrm{kOe}$. From the $\mathrm{M}$ vs $\mathrm{H}$ curve $(\mathrm{M}=$ Magnetization; $\mathrm{H}=$ Magnetic Field), we obtained the DC (direct current) susceptibility by angular coefficient of the linear fit up to 500 Oe. The resulting mass susceptibility is calculated according to the mass of each sample.

\section{RESULTS}

\section{MORPHOLOGY}

As first mentioned in the history of the fall, the first mass of Serra Pelada weighed about $6 \mathrm{~kg}$. 
It has been broken and distributed among local inhabitants. The second mass, which weighs 5.4 $\mathrm{kg}$ was shaped like a rounded pyramid, having dimensions of $25 \times 12.5 \times 12 \mathrm{~cm}$ and was nearly $80 \%$ covered with fusion crust. Many fragments of the first mass showed that most of the samples have a glassy and shiny black fusion crust of about $1.0 \mathrm{~mm}$ in thickness. Some pieces also show a crust with flow lines, which are typical for eucrites.

Stereomicroscope examinations of the cut surfaces of various slices, hand specimens and thin sections reveal a heterogeneous, brecciated appearance (Figure 1). The clasts range in size from millimeters to centimeters, in shape from oblate to rectangular, and in texture from very fine to coarse grained. The matrix between the clasts is gray and comprises an overall magmatic intergrowth assemblage of plagioclase and pyroxene.

\section{PETROGRAPHY AND MINERAL CHEMISTRY}

Macroscopic analysis of Serra Pelada showed that this meteorite is brecciated in nature (Figs. 1-2) with different kinds of clasts and distinct textural features (Figs. 1-3). Petrographic study revealed different textures of rock fragments embedded within a well-consolidated matrix. Here the textural terminology and abbreviations follow that used by Yamaguchi et al. (1994): MM - clastic fine to medium grained matrix ( 0.05 to $0.1 \mathrm{~mm})$ rich in lithic clasts and mineral fragments ranging from 0.05 to $0.8 \mathrm{~mm}$. The matrix presents a fragmented aspect and it is difficult to identify the borders of most of the clasts (Fig. 3a); FX - very fine grained clast of equigranular subophitic and ophitic textures composed of pyroxenes $(<0.07 \mathrm{~mm})$ and plagioclase of the same size range (shock melt veins are present within this clast) (Fig. 3b); CX - coarse grained

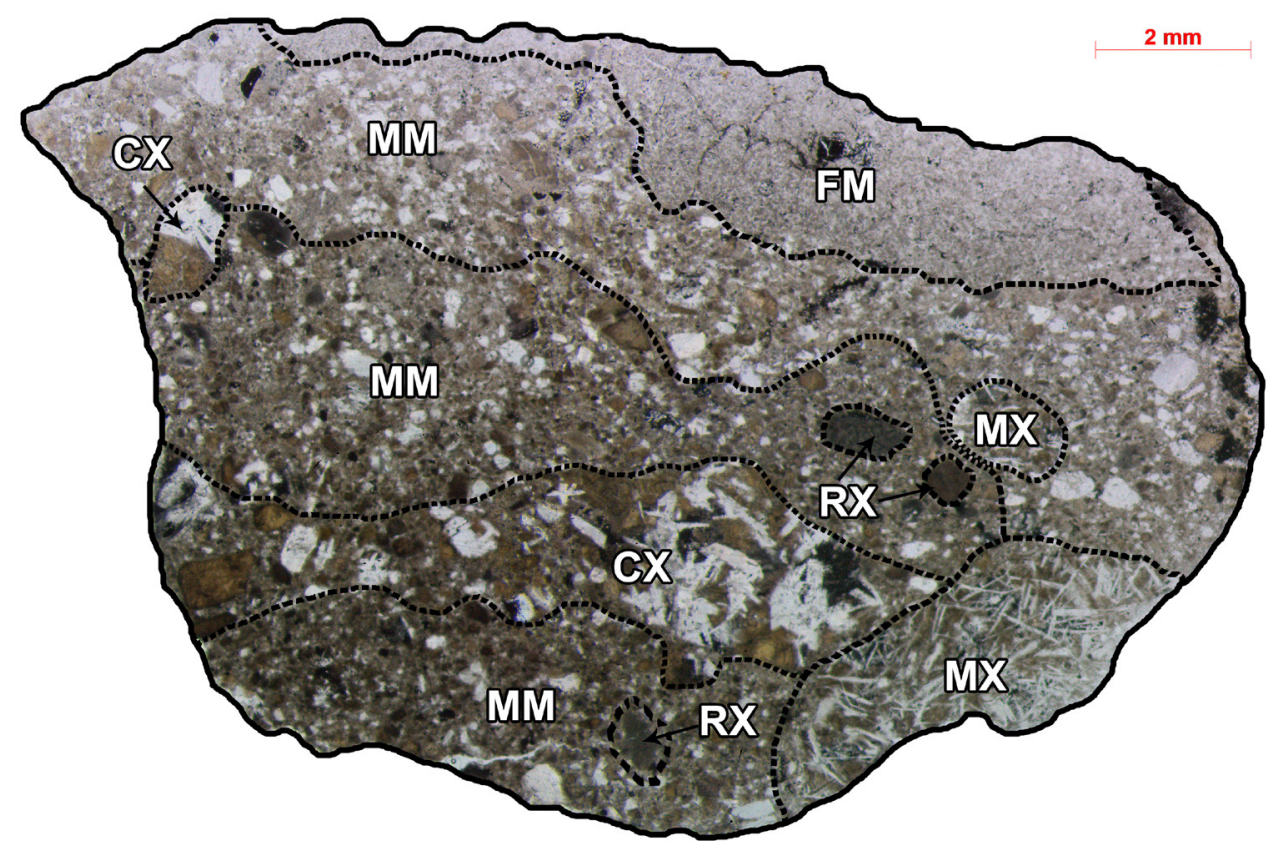

Figure 2 - Picture of a thin section in transmitted light. A variety of light and dark angular clasts range in size from millimeters to centimeters. The lithologies are outlined with dashed lines for better visualization. The matrix and clasts are identified by letters as indicated in the text of the paper. White areas are plagioclase, medium brown areas are clinopyroxene and small black spots are melts and opaque minerals. The abreviations are those presented in figure 3. 

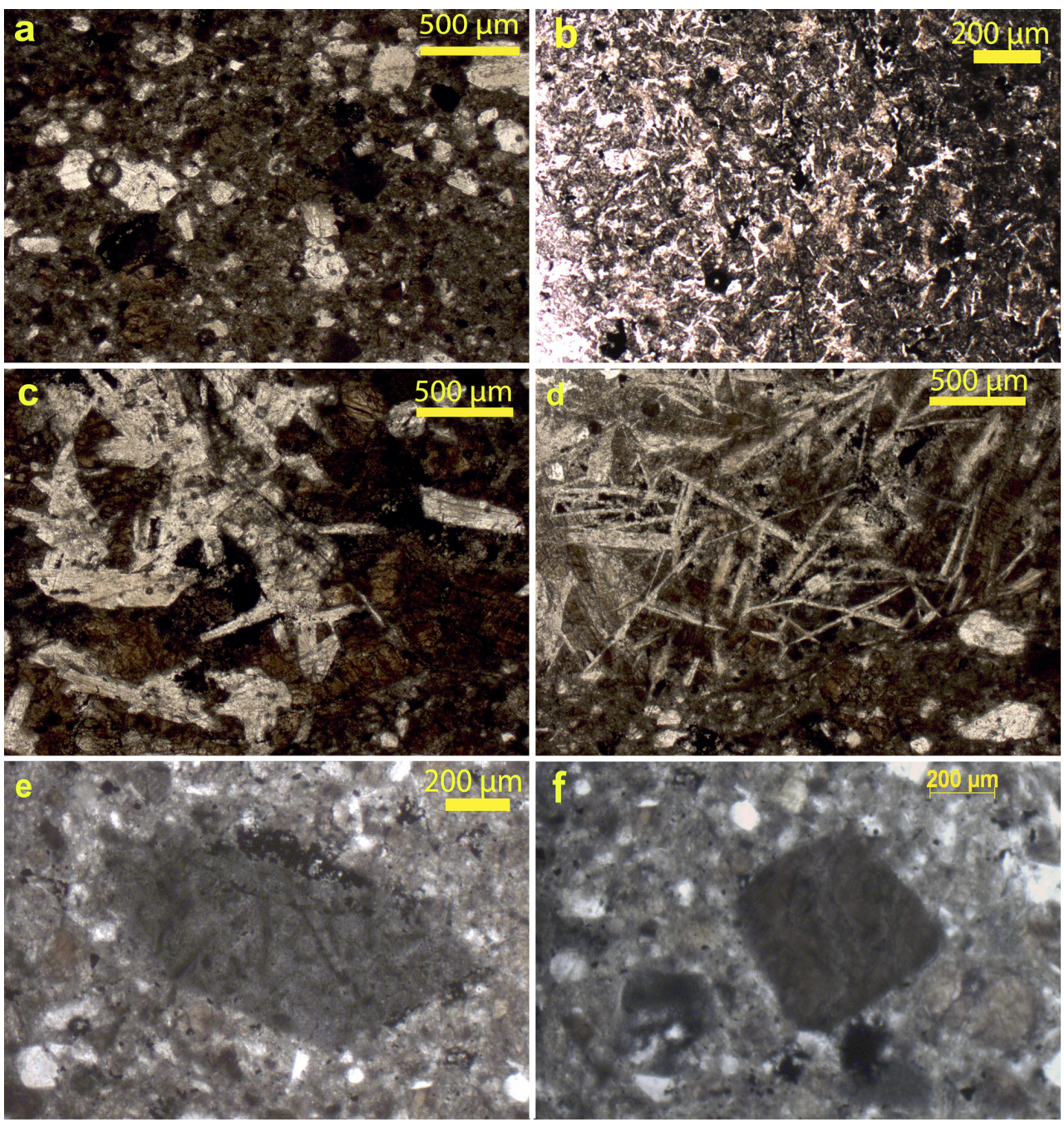

Figure 3 - Transmitted plane polarized light photomicrographs of Serra Pelada showing variability of clast type: (a) MM - clastic fine to medium grained matrix , b) FX - very fine grained clast, c) CX coarse grained clasts, d) MX - Medium grained clasts, e-f) RX - recrystallized impact melts.

clasts with gabbroic subophitic texture. Fractured anhedral to subhedral pyroxenes (0.6 to $1 \mathrm{~mm}$ ) show mosaicism and opaque inclusions while plagioclase ( 0.25 to $0.8 \mathrm{~mm})$ shows undulatory extinction (Fig. 3c); MX - Medium grained clasts with subophitic texture. Fractured pyroxene $(0.2$ to $0.5 \mathrm{~mm}$ ) containing opaque inclusions and mosaicism. Needles of plagioclase ranging from 0.2 to $0.8 \mathrm{~mm}$ show undulatory extinction (Fig. 3d); $\mathbf{R X}$ - recrystallized impact melts (Fig. 3e-f).

Shock features in Serra Pelada are somewhat heterogeneous among the various lithologies.
Mostly plagioclase crystals in the entire meteorite preserve their original lath shape and show weak undulatory extinction, although it is difficult to verify in the FX-clasts, due to their small grain size. Many pyroxenes of the CX-clasts are fractured and show mosaic texture. Over some areas, both in the matrix and in the clasts, there are small melt pockets and network-like glassy veins. These veins are composed of mafic glass containing very fine and partly molten minerals. Since no maskelynite is present nor are planar deformation features observed in pyroxenes, the shock stage is estimated 
to be S3, according to shock metamorphism features proposed for shock classification by Stöffler et al. (1991) and Rubin et al. (1997).

\section{MINERALOGY}

The matrix and clasts of Serra Pelada are composed mainly of calcic plagioclase feldspar and clinopyroxenes, with variable composition. Accessory minerals are quartz, apatite and opaque minor phases that include Ni-poor iron, troilite, ilmenite and chromite.
Pyroxene: Pyroxene is identified to be dominantly pigeonite (MM: $\mathrm{En}_{26-29} \mathrm{Wo}_{4-29} \mathrm{Fs}_{34-61}$; FX: $\mathrm{En}_{25-33} \mathrm{Wo}_{8-20} \mathrm{Fs}_{40-60} ; \mathbf{M X}: \mathrm{En}_{33-39} \mathrm{Wo}_{7-14} \mathrm{Fs}_{53-}$ ${ }_{63} \mathbf{C X}: \mathrm{En}_{29-39} \mathrm{Wo}_{7-37} \mathrm{Fs}_{33-56}$ ) (Figure 4). Many of these grains in matrix and clasts have exsolved lamellae of augite (Figure 5a, b). The quantitative WDS analysis composition of the pyroxene for each lithology present in Serra Pelada are given in Table I. Some grains have a cloudy appearance due to many tiny opaque mineral inclusions (several microns to submicron dimension) which is a

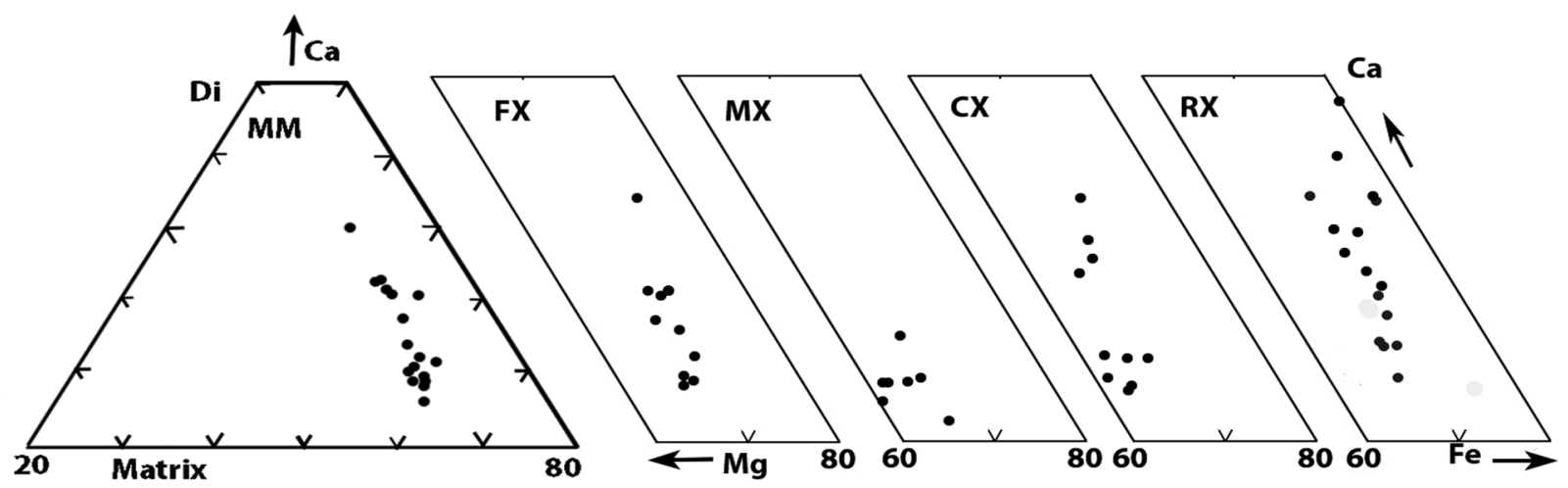

Figure 4 - Pyroxene ternary diagram showing the composition of pyroxene in matrix and clasts in Serra Pelada meteorite.
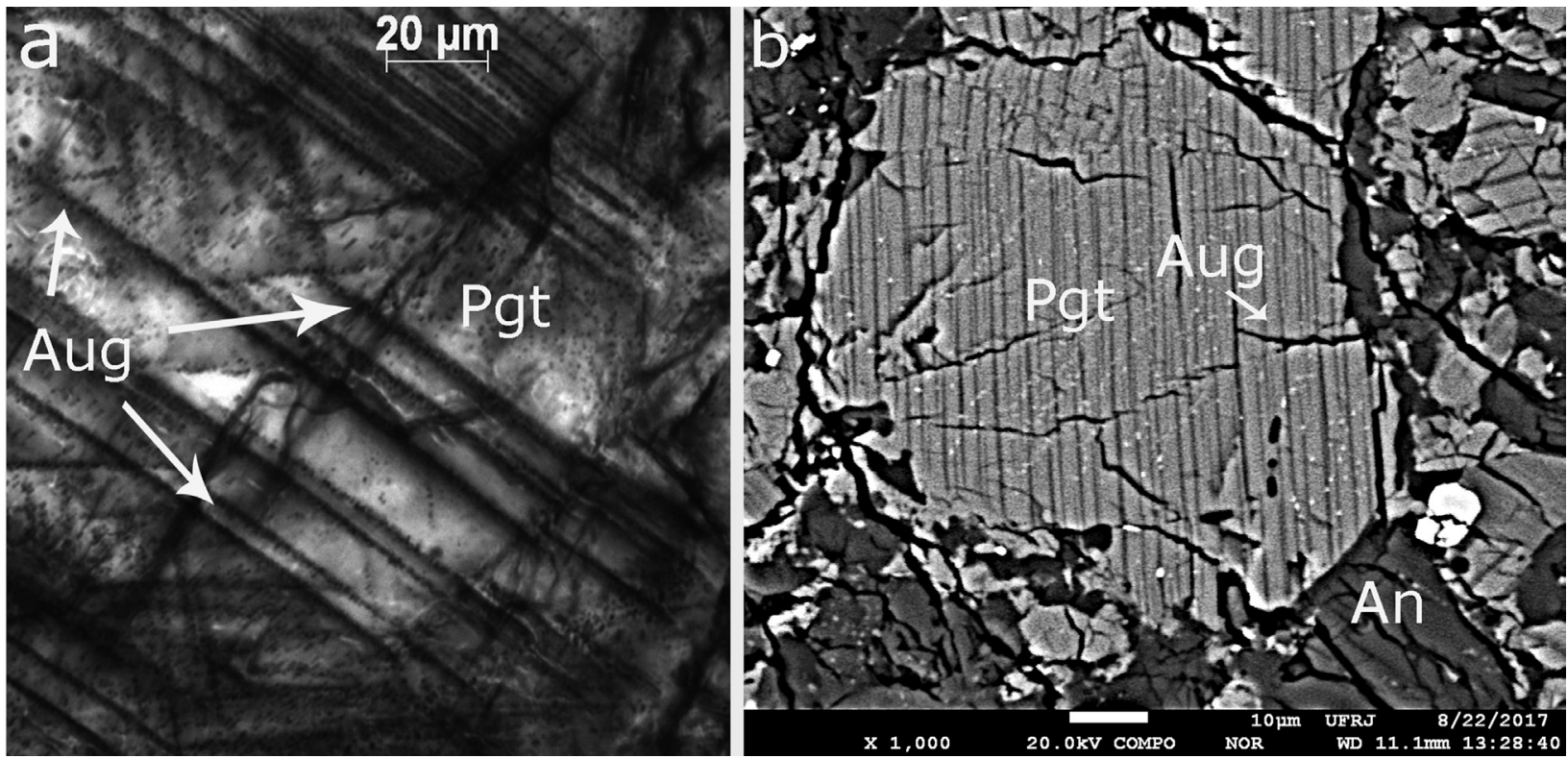

Figure 5 - Pyroxene of Serra Pelada showing pigeonite and augite exsolution lamellae as dark lines. a) Transmitted plane polarized light photomicrograph b) back scattered electron (BSE) image. Pgt: pigeonite; Aug: augite; An: Anothite-bytownite. 
TABLE I

Major and trace element composition of pyroxenes from the different lithologies present in Serra Pelada meteorite. Quantitative WDS analysis in wt. \%.

\begin{tabular}{|c|c|c|c|c|c|c|c|c|c|c|}
\hline & $\begin{array}{c}\mathrm{Al2O3} \\
\text { wt } \%\end{array}$ & $\begin{array}{l}\text { MgO } \\
\text { wt \% }\end{array}$ & $\begin{array}{l}\mathrm{SiO2} \\
\text { wt \% }\end{array}$ & $\begin{array}{c}\mathrm{FeO} \\
\text { wt \% }\end{array}$ & $\begin{array}{r}\mathrm{CaO} \\
\text { wt \% }\end{array}$ & $\begin{array}{l}\mathrm{TiO2} \\
\text { wt \% }\end{array}$ & $\begin{array}{c}\mathrm{Cr} 2 \mathrm{O3} \\
\text { wt \% }\end{array}$ & $\begin{array}{l}\text { MnO } \\
\text { wt \% }\end{array}$ & $\begin{array}{r}\mathrm{CoO} \\
\text { wt } \%\end{array}$ & $\begin{array}{l}\text { Total } \\
\text { wt } \%\end{array}$ \\
\hline \multirow{10}{*}{ 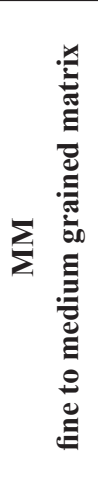 } & 0.877 & 10.359 & 49.054 & 27.388 & 10.532 & 0.282 & 0.726 & 0.839 & 0.000 & 100.057 \\
\hline & 0.400 & 10.926 & 48.823 & 34.428 & 3.951 & 0.072 & 0.310 & 1.081 & 0.000 & 99.991 \\
\hline & 0.559 & 10.697 & 48.943 & 33.846 & 3.906 & 0.105 & 1.232 & 1.031 & 0.000 & 100.319 \\
\hline & 0.794 & 10.053 & 48.809 & 28.507 & 9.584 & 0.277 & 1.356 & 0.900 & 0.004 & 100.284 \\
\hline & 0.227 & 11.160 & 49.757 & 33.646 & 4.580 & 0.075 & 0.154 & 1.053 & 0.000 & 100.652 \\
\hline & 0.333 & 11.056 & 49.515 & 33.587 & 4.684 & 0.061 & 0.204 & 1.089 & 0.000 & 100.529 \\
\hline & 1.455 & 10.179 & 49.614 & 24.129 & 14.054 & 0.177 & 0.486 & 0.717 & 0.000 & 100.811 \\
\hline & 0.597 & 10.205 & 48.814 & 27.766 & 10.567 & 0.342 & 0.524 & 0.871 & 0.000 & 99.686 \\
\hline & 0.456 & 11.198 & 49.879 & 33.631 & 4.520 & 0.017 & 0.159 & 1.072 & 0.004 & 100.936 \\
\hline & 1.428 & 9.926 & 48.154 & 28.151 & 10.919 & 0.231 & 1.072 & 0.864 & 0.000 & 100.745 \\
\hline \multirow{10}{*}{ 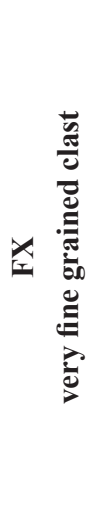 } & 0.879 & 10.230 & 49.456 & 28.723 & 9.596 & 0.170 & 0.339 & 0.871 & 0.000 & 100.264 \\
\hline & 0.515 & 9.898 & 49.296 & 29.901 & 9.312 & 0.180 & 0.300 & 0.929 & 0.000 & 100.331 \\
\hline & 0.315 & 9.897 & 49.371 & 33.971 & 5.342 & 0.131 & 0.242 & 1.080 & 0.000 & 100.349 \\
\hline & 0.494 & 9.633 & 49.493 & 29.953 & 9.618 & 0.169 & 0.430 & 0.956 & 0.013 & 100.759 \\
\hline & 3.711 & 9.428 & 47.196 & 30.486 & 6.636 & 0.121 & 0.285 & 0.949 & 0.000 & 98.812 \\
\hline & 0.295 & 10.991 & 49.771 & 34.849 & 3.708 & 0.104 & 0.150 & 1.061 & 0.000 & 100.929 \\
\hline & 0.554 & 10.541 & 49.063 & 30.275 & 7.555 & 0.145 & 0.557 & 0.956 & 0.000 & 99.646 \\
\hline & 9.917 & 7.209 & 47.637 & 20.386 & 13.097 & 0.075 & 0.152 & 0.658 & 0.000 & 99.131 \\
\hline & 0.576 & 10.509 & 48.544 & 34.885 & 3.944 & 0.140 & 0.269 & 1.110 & 0.000 & 99.977 \\
\hline & 0.446 & 10.756 & 48.842 & 34.609 & 4.300 & 0.130 & 0.791 & 1.022 & 0.000 & 100.896 \\
\hline \multirow{9}{*}{ 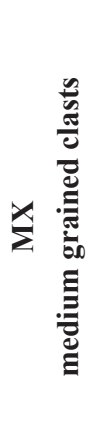 } & 0.454 & 12.913 & 47.280 & 32.056 & 3.684 & 0.116 & 0.935 & 1.012 & 0.000 & 98.450 \\
\hline & 0.281 & 12.190 & 43.190 & 40.915 & 1.396 & 0.017 & 0.410 & 1.157 & 0.000 & 99.556 \\
\hline & 0.464 & 12.713 & 49.982 & 32.267 & 3.736 & 0.105 & 0.477 & 0.957 & 0.011 & 100.712 \\
\hline & 0.758 & 11.129 & 49.187 & 31.032 & 6.645 & 0.102 & 0.906 & 0.970 & 0.000 & 100.729 \\
\hline & 0.585 & 12.050 & 48.675 & 33.872 & 3.839 & 0.105 & 1.060 & 1.032 & 0.000 & 101.218 \\
\hline & 0.807 & 11.818 & 47.399 & 33.622 & 3.599 & 0.121 & 1.239 & 1.022 & 0.006 & 99.633 \\
\hline & 0.455 & 11.213 & 47.973 & 33.764 & 3.980 & 0.196 & 0.929 & 1.066 & 0.000 & 99.576 \\
\hline & 0.412 & 13.233 & 48.727 & 32.347 & 2.599 & 0.101 & 0.559 & 1.035 & 0.000 & 99.013 \\
\hline & 0.412 & 13.034 & 49.149 & 32.408 & 3.708 & 0.062 & 0.415 & 1.001 & 0.000 & 100.189 \\
\hline \multirow{10}{*}{ 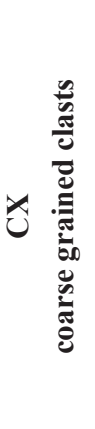 } & 0.708 & 13.094 & 49.300 & 31.585 & 4.036 & 0.068 & 0.787 & 0.983 & 0.000 & 100.561 \\
\hline & 0.455 & 12.411 & 49.569 & 33.181 & 3.191 & 0.022 & 0.346 & 1.058 & 0.000 & 100.233 \\
\hline & 0.580 & 12.626 & 49.658 & 30.397 & 5.454 & 0.084 & 0.308 & 1.022 & 0.000 & 100.129 \\
\hline & 0.378 & 12.377 & 49.085 & 33.360 & 3.497 & 0.081 & 0.625 & 1.093 & 0.000 & 100.496 \\
\hline & 1.026 & 11.571 & 49.804 & 31.210 & 5.152 & 0.097 & 0.279 & 1.021 & 0.000 & 100.160 \\
\hline & 0.466 & 11.002 & 49.501 & 33.226 & 5.297 & 0.087 & 0.366 & 1.036 & 0.000 & 100.981 \\
\hline & 1.205 & 11.820 & 49.884 & 25.598 & 10.824 & 0.167 & 0.450 & 0.850 & 0.000 & 100.798 \\
\hline & 0.471 & 12.405 & 49.602 & 33.415 & 3.033 & 0.080 & 0.437 & 1.081 & 0.011 & 100.535 \\
\hline & 1.002 & 11.333 & 49.846 & 26.339 & 10.592 & 0.118 & 0.584 & 0.839 & 0.000 & 100.653 \\
\hline & 1.186 & 10.610 & 49.823 & 24.595 & 12.780 & 0.157 & 0.441 & 0.773 & 0.012 & 100.377 \\
\hline
\end{tabular}


TABLE I (continuation)

\begin{tabular}{|c|c|c|c|c|c|c|c|c|c|c|}
\hline & $\begin{array}{c}\mathrm{A} 12 \mathrm{O3} \\
\text { wt } \%\end{array}$ & $\begin{array}{l}\text { MgO } \\
\text { wt \% }\end{array}$ & $\begin{array}{l}\mathrm{SiO2} \\
\text { wt \% }\end{array}$ & $\begin{array}{c}\mathrm{FeO} \\
\text { wt \% }\end{array}$ & $\begin{array}{c}\mathrm{CaO} \\
\text { wt } \%\end{array}$ & $\begin{array}{l}\mathrm{TiO} 2 \\
\text { wt } \%\end{array}$ & $\begin{array}{c}\text { Cr2O3 } \\
\text { wt } \%\end{array}$ & $\begin{array}{l}\text { MnO } \\
\text { wt \% }\end{array}$ & $\begin{array}{r}\mathrm{CoO} \\
\text { wt } \%\end{array}$ & $\begin{array}{l}\text { Total } \\
\text { wt \% }\end{array}$ \\
\hline \multirow{10}{*}{ 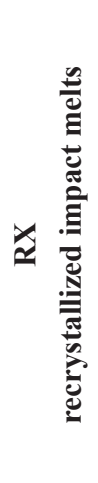 } & 0.854 & 10.043 & 48.688 & 26.711 & 12.053 & 0.244 & 1.042 & 0.821 & 0.000 & 100.456 \\
\hline & 6.852 & 8.558 & 47.822 & 25.582 & 9.647 & 0.126 & 0.433 & 0.816 & 0.000 & 99.836 \\
\hline & 7.809 & 7.801 & 46.940 & 22.861 & 11.490 & 0.242 & 0.938 & 0.685 & 0.003 & 98.769 \\
\hline & 0.809 & 10.031 & 48.364 & 25.225 & 13.714 & 0.304 & 0.843 & 0.756 & 0.000 & 100.046 \\
\hline & 4.893 & 9.485 & 49.144 & 28.005 & 7.867 & 0.017 & 0.068 & 0.887 & 0.000 & 100.366 \\
\hline & 3.190 & 9.315 & 44.911 & 30.414 & 7.595 & 3.980 & 0.074 & 0.852 & 0.000 & 100.331 \\
\hline & 0.317 & 10.707 & 48.947 & 35.324 & 3.778 & 0.233 & 0.300 & 1.118 & 0.000 & 100.724 \\
\hline & 5.252 & 9.946 & 48.903 & 30.448 & 5.706 & 0.185 & 0.061 & 0.937 & 0.000 & 101.438 \\
\hline & 6.535 & 9.039 & 48.544 & 30.239 & 5.460 & 0.095 & 0.070 & 0.925 & 0.000 & 100.907 \\
\hline & 6.473 & 9.807 & 48.144 & 31.850 & 3.700 & 0.044 & 0.059 & 1.036 & 0.000 & 101.113 \\
\hline
\end{tabular}

predominant feature in basaltic eucrites as reported in the literature (e.g. Hutchinson 2004).

Feldspar: Calcic feldspar occurs in all clasts and variable in average composition from $\mathrm{An}_{81}$ to $\mathrm{An}_{93}$, which is similar in composition to typical basaltic eucrites of $A_{75-94}$ (e.g., Mittlefehldt 2015). Many clasts show ophitic/sub-ophitic textures, defined by the presence of subhedral laths of plagioclase feldspars embedded in pyroxene grains. Feldspar also shows a cloudy appearance due many opaque inclusions, also found in the pyroxenes. Most of the feldspar grains have a composition similar to bytownite, whereas a couple of them show anorthite composition (Figure 6). Table II shows the quantitative WDS analysis composition of the plagioclase present in the matrix and clasts.

Accessory minerals: The presence of $\mathrm{SiO}_{2}$ has been identified as quartz by its Raman spectrum and is a common accessory mineral noticed mostly as inclusions within the plagioclase and also less common within pyroxene. In addition, it occurs in the interstices between plagioclase and pyroxene. Apatite also occurs in minor amounts.

The main opaque phases are troilite and ilmenite, minor amounts of $\mathrm{Ni}$-poor $\mathrm{Fe}$ and chromite. There are no systematic differences in chemical compositions between mineral phases in different textural regions. Average composition of ilmenite $\left(\mathrm{TiO}_{2}=\sim 51 \mathrm{wt} \% \mathrm{FeO}=\sim 43 \mathrm{wt} \%\right)$ is consistent with this mineral in other basaltic eucrites (Mayne et al. 2009, Mittlefehldt 2015). Chromite and ulvöspinel occur as accessory phases in sizes up to tens of microns. These chromite/ ulvöspinel grains are common minor minerals in basaltic eucrites (Mittlefehldt 2015).

The measurements of the magnetic susceptibility showed that $\log \chi\left(10^{-9} \mathrm{~m}^{3} / \mathrm{kg}\right)$ is about 2.9 and the density is $2.77 \mathrm{~g} / \mathrm{cm}^{3}$.

\section{DISCUSSION}

Petrographic properties and mineral chemistry data of Serra Pelada are typical of eucrites of the HED clan and confirm its origin from asteroid 4 Vesta (Figure 7 and Table III). It is a monomict breccia with lithic and mineral clasts set in a matrix of fine to medium-grained mineral fragments. As observed in most of the known eucrites, there are no systematic differences in chemical compositions of minerals among different textural regions.

The chemical data are broadly consistent with literature values for noncumulate eucrites, although $\mathrm{TiO}_{2}$ values are lower than those presented by Barrat et al. (2000) (Figure 8).

As indicated in figure 4, pyroxene compositions of matrix and clasts plot along a single tie line in the pyroxene quadrilateral regardless of the texture. 


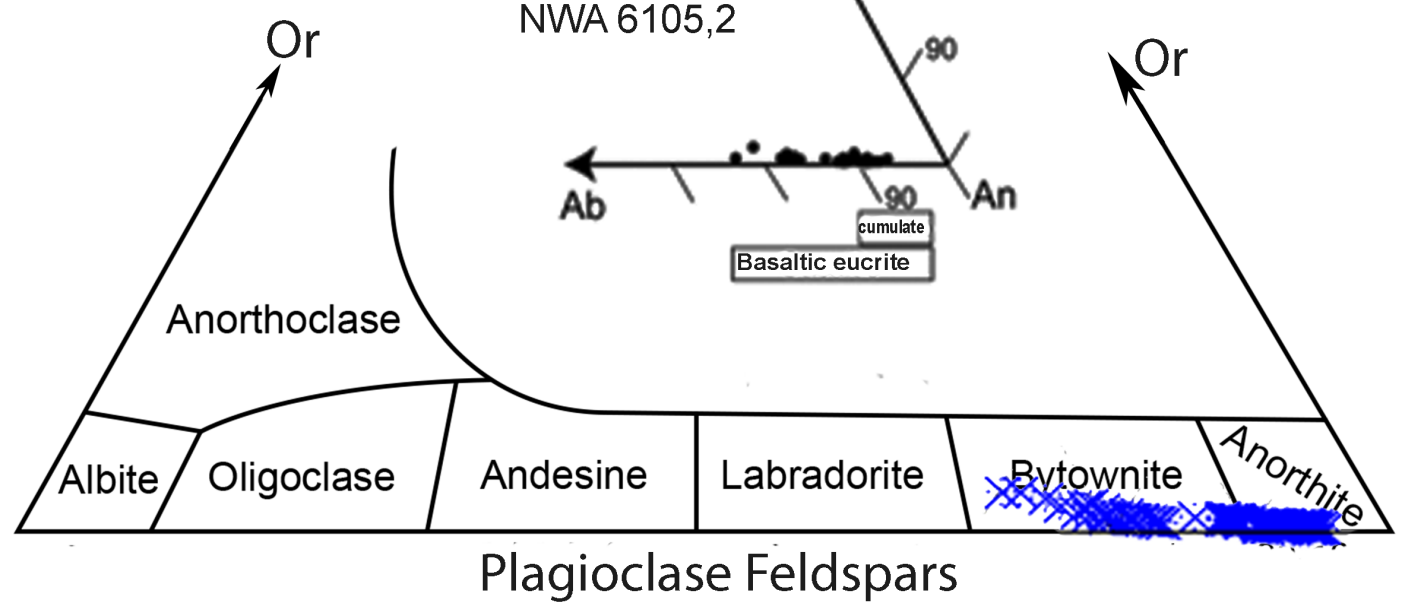

Figure 6 - An-Ab-Or ternary diagram depicting the plagioclase compositions in Serra Pelada compared with NWA 6105,2 (McSween et al. 2011).

TABLE II

Major and trace element composition of plagioclase from the different lithologies present in Serra Pelada meteorite. Quantitative WDS analysis in wt. \%.

\begin{tabular}{|c|c|c|c|c|c|c|c|c|c|c|c|}
\hline & $\begin{array}{l}\text { Na2O } \\
\text { wt } \%\end{array}$ & $\begin{array}{c}\mathrm{Al} 2 \mathrm{O3} \\
\text { wt \% }\end{array}$ & $\begin{array}{l}\mathrm{SiO} 2 \\
\text { wt } \%\end{array}$ & $\begin{array}{l}\text { MgO } \\
\text { wt \% }\end{array}$ & $\begin{array}{c}\mathrm{CaO} \\
\text { wt } \%\end{array}$ & $\begin{array}{c}\text { FeO } \\
\text { wt } \%\end{array}$ & $\begin{array}{l}\text { K2O } \\
\text { wt \% }\end{array}$ & $\begin{array}{r}\text { TiO2 } \\
\text { wt } \%\end{array}$ & $\begin{array}{l}\text { MnO } \\
\text { wt \% }\end{array}$ & $\begin{array}{c}\mathrm{Cr} 2 \mathrm{O3} \\
\text { wt } \%\end{array}$ & $\begin{array}{l}\text { Total } \\
\text { wt } \%\end{array}$ \\
\hline \multirow{10}{*}{$\sum$} & 0.537 & 36.256 & 44.002 & 0.043 & 18.772 & 0.354 & 0.063 & 0.000 & 0.000 & 0.000 & 100.027 \\
\hline & 0.853 & 35.018 & 45.495 & 0.001 & 17.913 & 0.277 & 0.091 & 0.000 & 0.000 & 0.010 & 99.658 \\
\hline & 0.782 & 35.372 & 45.533 & 0.022 & 17.799 & 0.248 & 0.053 & 0.000 & 0.000 & 0.014 & 99.823 \\
\hline & 2.874 & 31.056 & 51.160 & 0.068 & 13.957 & 0.292 & 0.575 & 0.022 & 0.000 & 0.000 & 100.004 \\
\hline & 0.746 & 35.949 & 44.734 & 0.009 & 18.346 & 0.233 & 0.054 & 0.007 & 0.000 & 0.004 & 100.082 \\
\hline & 0.575 & 36.336 & 44.281 & 0.032 & 18.708 & 0.153 & 0.072 & 0.020 & 0.049 & 0.000 & 100.226 \\
\hline & 0.816 & 35.573 & 45.553 & 0.018 & 17.899 & 0.151 & 0.099 & 0.011 & 0.000 & 0.011 & 100.131 \\
\hline & 0.771 & 35.283 & 45.584 & 0.129 & 17.847 & 0.480 & 0.082 & 0.000 & 0.032 & 0.002 & 100.210 \\
\hline & 1.945 & 33.495 & 47.150 & 0.264 & 16.610 & 0.857 & 0.164 & 0.054 & 0.042 & 0.017 & 100.598 \\
\hline & 1.201 & 34.641 & 46.980 & 0.016 & 16.750 & 0.367 & 0.180 & 0.038 & 0.018 & 0.005 & 100.196 \\
\hline \multirow{10}{*}{ 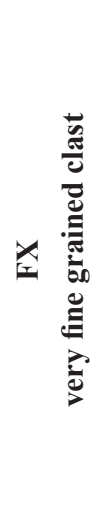 } & 1.195 & 33.570 & 47.835 & 0.088 & 16.363 & 0.584 & 0.160 & 0.000 & 0.000 & 0.019 & 99.814 \\
\hline & 1.071 & 34.198 & 46.858 & 0.057 & 16.706 & 0.418 & 0.142 & 0.011 & 0.000 & 0.036 & 99.497 \\
\hline & 1.869 & 33.548 & 46.954 & 0.145 & 15.988 & 0.988 & 0.200 & 0.000 & 0.000 & 0.016 & 99.708 \\
\hline & 1.789 & 34.077 & 47.419 & 0.059 & 16.498 & 0.351 & 0.147 & 0.042 & 0.048 & 0.000 & 100.430 \\
\hline & 0.928 & 31.495 & 50.456 & 0.036 & 15.745 & 0.287 & 0.096 & 0.035 & 0.000 & 0.000 & 99.078 \\
\hline & 0.975 & 35.125 & 46.282 & 0.033 & 17.432 & 0.337 & 0.065 & 0.003 & 0.011 & 0.019 & 100.282 \\
\hline & 0.900 & 34.386 & 45.765 & 0.315 & 17.037 & 1.627 & 0.041 & 0.073 & 0.062 & 0.026 & 100.232 \\
\hline & 0.864 & 34.586 & 46.358 & 0.096 & 17.370 & 0.597 & 0.122 & 0.000 & 0.004 & 0.006 & 100.003 \\
\hline & 0.044 & 0.691 & 97.472 & 0.020 & 0.250 & 0.222 & 0.027 & 0.091 & 0.004 & 0.003 & 98.824 \\
\hline & 0.907 & 34.638 & 46.260 & 0.119 & 17.446 & 0.366 & 0.109 & 0.050 & 0.029 & 0.000 & 99.924 \\
\hline
\end{tabular}


TABLE II (continuation)

\begin{tabular}{|c|c|c|c|c|c|c|c|c|c|c|c|}
\hline & $\begin{array}{l}\text { Na2O } \\
\text { wt } \%\end{array}$ & $\begin{array}{c}\text { Al2O3 } \\
\text { wt \% }\end{array}$ & $\begin{array}{l}\mathrm{SiO} 2 \\
\text { wt } \%\end{array}$ & $\begin{array}{l}\text { MgO } \\
\text { wt \% }\end{array}$ & $\begin{array}{c}\mathrm{CaO} \\
\text { wt } \%\end{array}$ & $\begin{array}{c}\text { FeO } \\
\text { wt \% }\end{array}$ & $\begin{array}{l}\text { K2O } \\
\text { wt \% }\end{array}$ & $\begin{array}{l}\mathrm{TiO2} \\
\text { wt } \%\end{array}$ & $\begin{array}{l}\text { MnO } \\
\text { wt \% }\end{array}$ & $\begin{array}{c}\mathrm{Cr} 2 \mathrm{O} 3 \\
\text { wt } \%\end{array}$ & $\begin{array}{l}\text { Total } \\
\text { wt } \%\end{array}$ \\
\hline \multirow{10}{*}{ 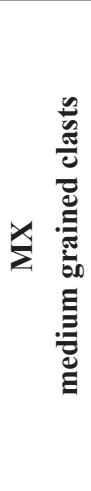 } & 1.390 & 33.224 & 47.740 & 0.278 & 16.024 & 0.801 & 0.208 & 0.023 & 0.020 & 0.000 & 99.708 \\
\hline & 2.045 & 34.001 & 47.409 & 0.090 & 16.299 & 0.629 & 0.193 & 0.000 & 0.002 & 0.014 & 100.682 \\
\hline & 1.832 & 34.265 & 47.041 & 0.157 & 16.662 & 0.657 & 0.142 & 0.000 & 0.000 & 0.000 & 100.756 \\
\hline & 1.182 & 34.312 & 47.137 & 0.049 & 16.818 & 0.409 & 0.160 & 0.002 & 0.077 & 0.000 & 100.146 \\
\hline & 0.962 & 34.971 & 46.015 & 0.035 & 17.169 & 0.248 & 0.088 & 0.000 & 0.066 & 0.000 & 99.554 \\
\hline & 0.608 & 35.928 & 44.611 & 0.101 & 17.999 & 0.555 & 0.101 & 0.000 & 0.032 & 0.000 & 99.935 \\
\hline & 1.194 & 33.533 & 47.054 & 0.219 & 16.422 & 1.018 & 0.204 & 0.004 & 0.003 & 0.025 & 99.676 \\
\hline & 1.082 & 35.015 & 46.434 & 0.022 & 17.152 & 0.312 & 0.134 & 0.019 & 0.000 & 0.009 & 100.179 \\
\hline & 2.354 & 33.835 & 47.801 & 0.104 & 15.766 & 0.664 & 0.250 & 0.014 & 0.031 & 0.000 & 100.819 \\
\hline & 1.177 & 34.362 & 46.802 & 0.085 & 16.467 & 0.466 & 0.196 & 0.001 & 0.019 & 0.019 & 99.594 \\
\hline \multirow{10}{*}{ 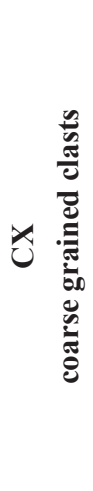 } & 0.817 & 35.385 & 45.087 & 0.013 & 17.707 & 0.223 & 0.079 & 0.000 & 0.006 & 0.000 & 99.317 \\
\hline & 1.157 & 34.381 & 46.767 & 0.100 & 16.847 & 0.243 & 0.177 & 0.003 & 0.000 & 0.000 & 99.675 \\
\hline & 0.732 & 35.943 & 44.557 & 0.037 & 18.064 & 0.179 & 0.057 & 0.006 & 0.004 & 0.024 & 99.603 \\
\hline & 2.031 & 34.177 & 47.224 & 0.104 & 16.403 & 0.431 & 0.190 & 0.017 & 0.000 & 0.000 & 100.577 \\
\hline & 0.812 & 35.704 & 45.736 & 0.022 & 17.724 & 0.124 & 0.122 & 0.022 & 0.000 & 0.020 & 100.286 \\
\hline & 0.846 & 35.823 & 44.982 & 0.000 & 17.960 & 0.203 & 0.070 & 0.015 & 0.000 & 0.009 & 99.908 \\
\hline & 0.945 & 35.606 & 45.651 & 0.011 & 17.436 & 0.208 & 0.127 & 0.000 & 0.037 & 0.000 & 100.021 \\
\hline & 1.079 & 34.492 & 46.201 & 0.206 & 16.932 & 1.095 & 0.118 & 0.000 & 0.064 & 0.010 & 100.197 \\
\hline & 0.759 & 35.992 & 44.958 & 0.027 & 18.022 & 0.196 & 0.083 & 0.022 & 0.000 & 0.000 & 100.059 \\
\hline & 1.871 & 34.350 & 47.319 & 0.025 & 16.558 & 0.250 & 0.184 & 0.011 & 0.001 & 0.000 & 100.569 \\
\hline \multirow{10}{*}{ 爻 } & 0.984 & 34.893 & 46.716 & 0.048 & 16.433 & 0.751 & 0.145 & 0.013 & 0.017 & 0.004 & 100.004 \\
\hline & 0.647 & 31.417 & 50.526 & 0.010 & 15.762 & 1.299 & 0.077 & 0.105 & 0.039 & 0.000 & 99.882 \\
\hline & 0.531 & 24.776 & 60.393 & 0.005 & 12.280 & 2.714 & 0.073 & 0.141 & 0.000 & 0.007 & 100.920 \\
\hline & 1.404 & 29.591 & 50.363 & 0.650 & 13.824 & 2.986 & 0.329 & 0.015 & 0.079 & 0.000 & 99.241 \\
\hline & 2.087 & 30.185 & 50.990 & 0.459 & 14.281 & 2.174 & 0.360 & 0.009 & 0.000 & 0.016 & 100.561 \\
\hline & 2.164 & 33.428 & 47.333 & 0.225 & 15.602 & 1.199 & 0.318 & 0.038 & 0.000 & 0.001 & 100.308 \\
\hline & 1.132 & 31.397 & 49.133 & 0.184 & 15.518 & 1.405 & 0.211 & 0.059 & 0.112 & 0.020 & 99.171 \\
\hline & 0.515 & 18.274 & 66.710 & 0.413 & 9.326 & 3.376 & 0.101 & 0.189 & 0.070 & 0.027 & 99.001 \\
\hline & 1.292 & 31.458 & 49.068 & 0.289 & 14.998 & 1.862 & 0.267 & 0.027 & 0.088 & 0.038 & 99.387 \\
\hline & 2.501 & 31.211 & 51.415 & 0.029 & 14.334 & 0.734 & 0.477 & 0.033 & 0.032 & 0.001 & 100.767 \\
\hline
\end{tabular}

TABLE III

Comparing Serra Pelada pyroxene and plagioclase data with others planetary basalts. These literature data were taken from Papike et al. (2003). Pyx: pyxroxene; An: Anothite-bytownite.

\begin{tabular}{cccccccccc}
\hline \multicolumn{2}{c}{ Earth } & \multicolumn{2}{c}{ Moon } & \multicolumn{2}{c}{ Mars } & \multicolumn{2}{c}{ 4-Vesta } & \multicolumn{2}{c}{ Serra Pelada } \\
\hline Pyx Fe/Mn & An \% & Pyx Fe/Mn & An \% & Pyx Fe/Mn & An \% & Pyx Fe/Mn & An \% & Pyx Fe/Mn & An \% \\
\hline $\mathrm{x}=40$ & $\mathrm{x}=69$ & $\mathrm{x}=62$ & $\mathrm{x}=89$ & $\mathrm{x}=32$ & $\mathrm{x}=49$ & $\mathrm{x}=30$ & $\mathrm{x}=87$ & $\mathrm{x}=32$ & $\mathrm{x}=89$ \\
$\mathrm{sd}=11$ & $\mathrm{sd}=12$ & $\mathrm{sd}=18$ & $\mathrm{sd}=3$ & $\mathrm{sd}=6$ & $\mathrm{sd}=5$ & $\mathrm{sd}=2$ & $\mathrm{sd}=2$ & $\mathrm{sd}=2$ & $\mathrm{sd}=5$ \\
$\mathrm{~N}=513$ & $\mathrm{~N}=474$ & $\mathrm{~N}=37$ & $\mathrm{~N}=243$ & $\mathrm{~N}=33$ & $\mathrm{~N}=39$ & $\mathrm{~N}=38$ & $\mathrm{~N}=35$ & $\mathrm{~N}=65$ & $\mathrm{~N}=62$ \\
\hline \hline
\end{tabular}




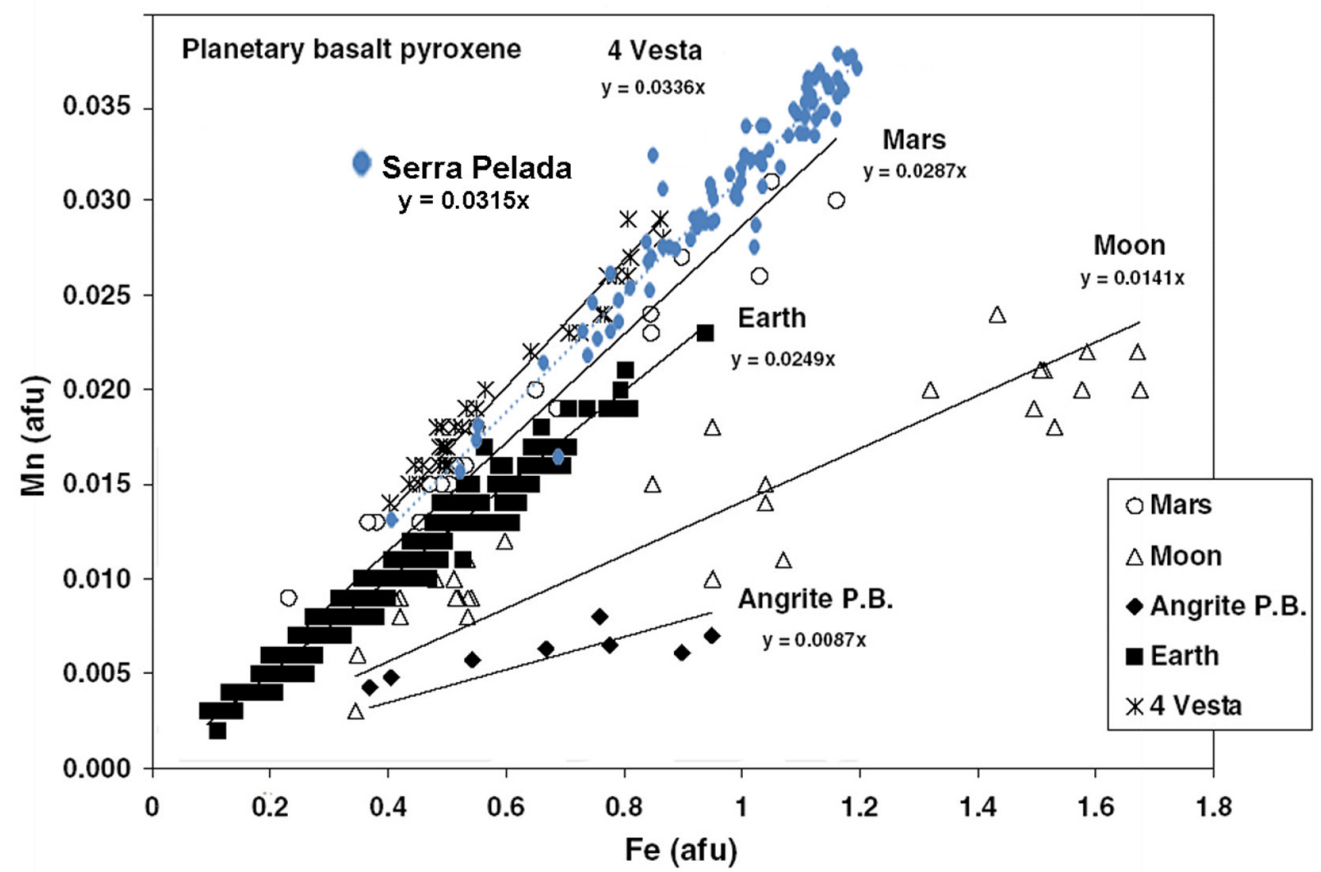

Figure 7 - Fe vs. Mn per 6-oxygen formula unit for pyroxene from planetary basalts, modified from Papike et al. (2003). The angular coefficient of Serra Pelada fits well with an origin from asteroid 4 Vesta.

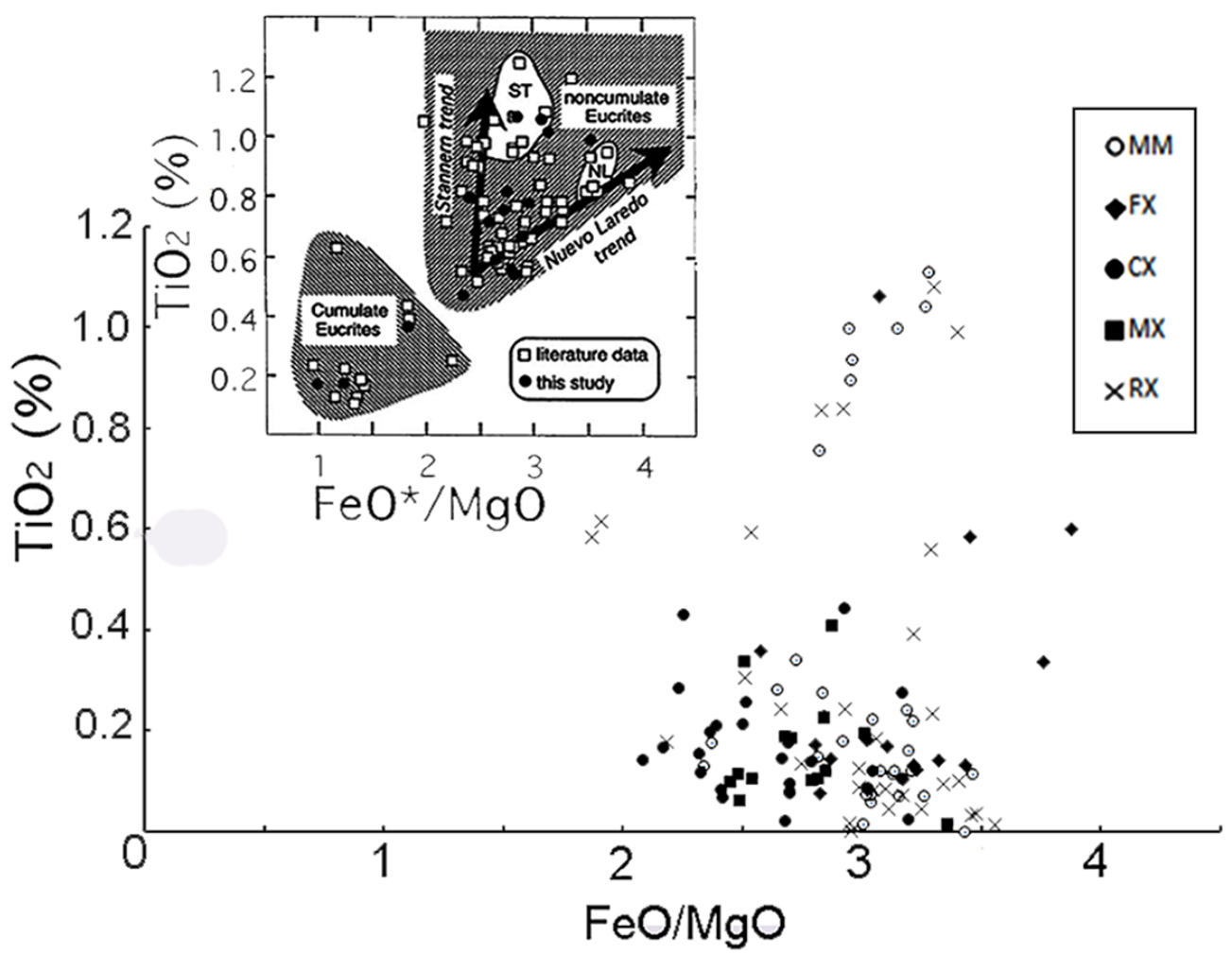

Figure 8 - Plot of $\mathrm{FeO} / \mathrm{MgO}$ vs. $\mathrm{TiO}_{2}$ for Serra Pelada eucrite, showing different ratios for each clast and matrix. This plot is compared with literature data taken from Barrat et al. (2000), the small figure inside the graph. 
However, the $\mathrm{Mg}$ concentration of pyroxene in the crystalline MX clasts is slightly higher than in other regions.

The Mn-Fe correlation of pyroxene in figure 7 shows that Serra Pelada has a slope of 0.03115 , which is close to 0.0336 value found by Papike et al. (2003) for 4 Vesta (but in fact this is an average trend line between diogenites and eucrites). Primitive bodies in the solar system can have different $\mathrm{Fe} / \mathrm{Mn}$ ratios in their silicate minerals as a consequence of volatility and oxidation state (Figure 9). The manganese enrichments in bodies such as 4 Vesta and Mars compared with the Earth and Moon have also been noted by Drake et al. (1989). These observations suggest that the Mn/ Fe ratio of materials can be used as a fingerprint of planetary provenance (Papike 1998).

The different textures among the CX, MX and FX clasts may be due to the location within different lava units. Comparing the percentage of $\mathrm{TiO}_{2}$ and $\mathrm{FeO} / \mathrm{MgO}$ ratio of Serra Pelada with the literature (Figure 8), the Serra Pelada $\mathrm{FeO} / \mathrm{MgO}$ ratio is located in the region close to that of noncumulate eucrites (Barrat et al. 2000), although the $\mathrm{TiO}_{2} \mathrm{wt} \%$ is lower than expected for these meteorites.

In our analysis, the amount of elemental titanium in chromite (ulvöspinel) is higher than in other eucrites, which may be linked to different degrees of oxidation. The reduced chrome and titanium in oxidizing conditions could be more abundant during the formation (Bunch and Keil 1971). High-Ti chromite grains are also a typical feature of highly metamorphosed eucrites due to the decomposition of spinel (Yamaguchi et al. 2001).

Using plagioclase as a classification method (Table III), the values for Serra Pelada, agree with those of 4 Vesta (Papike et al. 2003). Our results

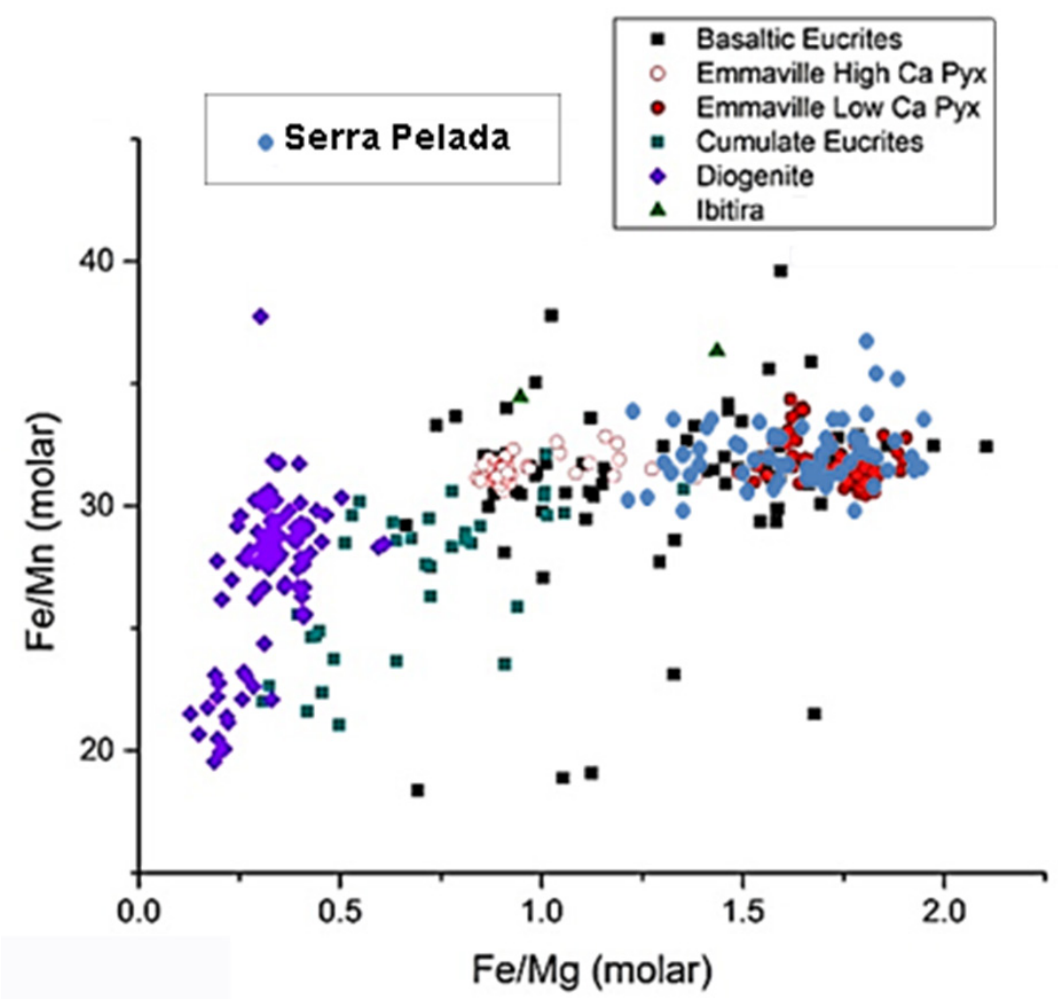

Figure 9 - Pyroxene Fe/Mg vs. Fe/Mn diagram. Basaltic eucrite, cumulate eucrite, diogenite and Ibitira data taken from Barret et al. (2015). Serra Pelada fits well within the low Ca basaltic eucrites. 
confirm that this can also be a useful method for planetary origin sorting.

Pyroxenes and plagioclases in the CX- and FXclasts have a cloudy appearance. This feature has been reported by Harlow and Klimentidis (1980) to be a predominant feature of basaltic eucrites, although there are variations for each meteorite. The observed cloudy appearance can be explained by metamorphism without recrystallization. As a result, iron in plagioclase exsolved into blebs and rods of iron oxides (Harlow and Klimentidis 1980).

Just as chondritic meteorites can be classified on the basis of thermal metamosphism, the eucrites also are classified into six exsolved types by Takeda and Graham (1991). These types reflect the cooling history of the eucrites, which is controlled by its depth in the parent body. The Serra Pelada fits well with type 5 mainly because of: 1) homogeneous chemical composition; 2) occurrence of cloudy pyroxene; 3) exsolution lamellae of augite in pigeonite; 4) recrystallized matrix, and 5) absence of inverted orthopyroxene.

The magnetic susceptibility $\log \chi\left(10^{-9} \mathrm{~m}^{3} /\right.$ $\mathrm{kg}$ ) about 2.9 corresponds well within the level of confidence to eucrite meteorites in the alignment chart given by Folco et al. (2006), revealing in this way, that it is a "magmatic" meteorite that comes from the asteroid belt.

Dawn's mission, which covered a large fraction of Vesta' surface, shows that the mineralogy is consistent with howardite-eucrite-diogenite (HED) meteorites (McSween et al. 2013). The howardite regolithic soil exhibits variable proportions of eucrite and diogenite material (De Sanctis et al. 2012, Ammannito et al. 2013). The study of HEDs allows a better understanding of the early differentiation of small bodies in the solar system subjected to low-gravity environments and post crystallization effects of impact metamorphism (Jasmeet et al. 2013).

\section{CONCLUSIONS}

Some remarkable attributes observed in Serra Pelada meteorite provide mineralogical and compositional information on diverse fragments. On the basis of petrography and mineral chemistry, we conclude that Serra Pelada is a basaltic monomict eucrite of Type 5 S3. It contains lithic and mineral clasts (mostly different varieties) indicating that the original igneous lithologies were subjected to postcrystallization thermal processing. These results help understand the surface of Vesta, covered by debris that resulted from impacts.

\section{ACKNOWLEDGMENTS}

Special thanks are given to Ricardo Josefides for providing samples for our studies and to the people of Serra Pelada for the attention they paid to this meteorite fall. Special thanks are also to Felipe Abrahão Monteiro for help with text, to Yara Ornellas for the assistance with EPMA analysis, and to Clarice Paixão for her wonderful coffee.

\section{REFERENCES}

AMMANNITO E ET AL. 2013. Vestan lithologies mapped by visual and ifrared spectrometer on Dawn. MAPS 48: 2185-2198.

BARRAT J, BLICHERT-TOFT J, GILLET P AND KELLER F. 2000. The differentiation of eucrites: The role of in situ crystallization. MAPS 35: 1087-1100.

BARRETT TJ, MITTLEFEHLDT DW, ROSS DK, GREENWOOD RC, ANAND M, FRANCHI IA, GRADY MM AND CHARLIER BLA. 2015. The mineralogy, petrography and composition of anomalous eucrite Emmaville. Proc Lunar Planet Sci Conf $46^{\text {th }}$, p. 16-20.

BINZEL RP AND XU S. 1993. Chips of asteroid 4 Vesta: Evidence for the parent body of basaltic achondrite meteorites. Science 260: 186-191.

BUNCH T AND KEIL K. 1971. Chromite and ilmenite in nonchondritic meteorites (Chromite and ilmenite analysis in pallasites, mesosiderites, achondrites and meteorites with electron microprobe). Am Mineral 56: 146-157.

DE SANCTIS MC ET AL. 2012. Spectroscopic Characterization of Mineralogy and Its Diversity Across Vesta. Science 336: 697-700. 
DRAKE MJ, NEWSOM HE AND CAPOBIANCO CJ. 1989. $\mathrm{V}, \mathrm{Cr}$, and $\mathrm{Mn}$ in the Earth, Moon, EPB and SPB and the origin of the Moon: Experimental studies. Geochim Cosmochim Acta 53: 2101-2111.

FOLCO L, ROCHETTE P, GATTACCECA J AND PERCHIAZZI N. 2006. In situ identification, pairing, and classification of meteorites from Antarctica through magnetic susceptibility measurements. MAPS 41: 343353.

HARLOW GE AND KLIMENTIDIS R. 1980. Clouding of pyroxenes and plagioclase in eucrites: Implications for post-crystallization processing. Proc Lunar Planet Sci Conf $11^{\text {th }}$, p. $1131-1143$.

JASMEET K, DHALIWA JK, CORDER CA, DAY JMD, PATCHEN AD AND TAYLOR LA. 2013. Petrology of the unbrecciated eucrite. Proc Lunar Planet Sci Conf $44^{\text {th }}$, p. 2434.

KEIL K. 2002. Geological history of asteroid 4 Vesta: The "smallest terrestrial planet". In: Bottke W, Cellino A, Paolicchoi and Binzel RP (Eds), Asteroids III, p. 573-584. University of Arizona Press, TucsoMcCord TB, Adams JB, and Johnson TV. 1970. Asteroid Vesta: Spectral reflectivity and compositional implications. Science 168: 1445-1447.

MAYNE RG, MCSWEEN JR HY, MCCOY TJ AND GALEA. 2009. Petrology of the unbrecciated eucrites. Geochim et Cosmochim Acta 73(3): 794-819.

MCSWEEN HY, MITTLEFEHLDT DW, BECK AW, MAYNE RG AND MCCOY TJ. 2011. HED meteorites and their relationship to the geology of Vesta and the Dawn mission. Space Sci Rev 163: 141-174.

MCSWEEN HY ET AL. 2013. Dawn; the Vesta-HED connection; and the geologic context for eucrites, diogenites, and howardites. MAPS 48: 2090-2104.

MITTLEFEHLDT DW. 2005. Ibitira: A basaltic achondrite from a distinct parent asteroid and implications for the Dawn mission. MAPS 40: 665-677.
MITTLEFEHLDT DW. 2014. Achondrites. In: Davis AM et al. (Eds), Meteorites and Cosmochemical Processes: Treatise on Geochemistry, Vol. 1, $2^{\text {nd }}$ ed., chapter 1.6, 2014.

MITTLEFEHLDT DW. 2015. Asteroid 4 Vesta: I. The howardite eucrite-diogenite (HED) clan of meteorites. Chem Erde 75: 155-183.

MITTLEFEHLDT DW, MCCOY TJ, GOODRICH CA AND KRACHER A 1998. Non-chondritic meteorites from asteroidal bodies. In: Papike JJ (Ed), Reviews in Mineralogy: Planetary Materials, Vol. 36, Chap. 4. Mineralogical Society of America, p. 1-195.

PAPIKE JJ. 1998. Comparative Planetary Mineralogy: Chemistry of Melt-derived Pyroxene, Feldspar, and Olivine: $29^{\text {th }}$ Annual Lunar and Planetary Science Conference, March 16-20, 1998, Houston, TX, abstract no. 1008 .

PAPIKE JJ, KARNER JM AND SHEARER CK. 2003. Determination of planetary basalt parentage: A simple technique using the electron microprobe. Am Mineral 88: 469-472.

RUBIN AE. 1997. Mineralogy of meteorite groups. MAPS 32: 231-247.

SRINIVASAN G, GOSWAM JN AND BHANDARI N. 1998. ${ }^{26} \mathrm{Al}$ in eucrite Piplia Kalan: Plausible heat source and formation chronology. Science 284: 1348-1350.

STÖFFLER D, KEIL K AND SCOTT ERD. 1991. Sock metamorphism of ordinary chondrites. Geochim Cosmochim Acta 55: 3845-3867.

TAKEDAHAND GRAHAMAL. 1991. Degree of equilibration of eucritic pyroxenes and thermal metamorphism of the earliest planetary crust. MAPS 26: 129-134.

YAMAGUCHI A, TAKEDA H, BORGARD D AND GARRISSON D. 1994. Textural variations and impact history of the Millbillillie eucrite. MAPS 29: 237-245.

YAMAGUCHI A ET AL. 2001. Post-crystallization reheating and partial melting of eucrite EET90020 by impact into the hot crust of asteroid 4 Vesta $\sim 4.50 \mathrm{Ga}$ ago. Geochim Cosmochim Acta 65: 3577-3599. 